$\mathrm{PH} 104_{\text {debale }}$

a debate Patrimonio cultural y cambio climático

| coordina Alejandro García Hermida

\title{
Patrimonio rural y cambio climático
}

José Manuel Baena Gallé | IES Luca de Tena (Sevilla), Consejería de Educación y Deporte, Junta de Andalucía

URL de la contribución <www.iaph.es/revistaph/index.php/revistaph/article/view/4982>

\section{Introducción}

Según el Ministerio español para la Transición Ecológica y el Reto Demográfico el cambio climático se define como la variación global del clima de la tierra por causas naturales o humanas. En ese sentido, remarca la idea de que el modo de producción y de consumo energético causan en gran medida el cambio climático (2021). Las consecuencias de este fenómeno resultan incalculables y tan negativas como impredecibles. El Alto Comisionado de las Naciones Unidas para los Refugiados (ACNUR) habla del coste humano del cambio climático, responsable del $75,8 \%$ de los nuevos desplazamientos internos en 2020; aproximadamente afecta a unos 30,7 millones de personas (Sciacia 2021).

\section{Patrimonio cultural y cambio climático}

¿Pero cómo afecta el cambio climático al patrimonio cultural? Una simple búsqueda en Internet aporta diversidad de resultados. En muchos de ellos se señala cómo el cambio climático perturba aquellos bienes declarados por la UNESCO Patrimonio Mundial, con toda la importancia simbólica de estos (UNESCO 2009). Pero no se puede señalar como única consecuencia la afectación que el cambio climático provoca en elementos materiales del patrimonio, sino que hay que ir más allá. Si se observa la información antes aludida de ACNUR, se concluye que tiene consecuencias mucho más terribles. Esta población que se desplaza abandona sus espacios vitales y deja de protegerlos y cuidarlos, pero también abandona sus formas de vida (relaciones sociales, costumbres, alimentación, etc.), con lo que se pierde un patrimonio inmaterial irrecuperable.

Evidentemente, una de las dimensiones que más incide en este asunto es la de carácter económico. Las grandes transformaciones industriales y productivas que se iniciaron con la Revolución Industrial y que se han ace- lerado en los últimos tiempos han provocado diversos fenómenos que precipitan el cambio climático. Estos cambios en los modos de producción han llevado a dos consecuencias fundamentales con respecto al patrimonio cultural. Por un lado, la desaparición y el abandono de formas de vida tradicionales que protegían el ecosistema y, asociados a ella, estructuras materiales que pierden su funcionalidad. Por otro lado, el aumento de un fenómeno de consumismo que potencia a su vez la producción y la no reutilización de muchos elementos que afectan a las dinámicas ambientales. Los avances tecnológicos y los cambios en los sistemas productivos han supuesto evidentes beneficios para la vida de los ciudadanos. No obstante, también ha traído consecuencias negativas como la producción masiva, el consumismo, la globalización, el uso de instrumentos y productos nocivos que afectan al clima provocando una transformación de muchos parámetros de nuestra vida. Entre ellos se encuentra la desaparición de todos aquellos elementos del patrimonio cultural relacionados con formas de vida anteriores: instalaciones, edificios, oficios, costumbres, gastronomía, etc. Esta estrecha relación entre ambos conceptos se puede observar en múltiples ejemplos a nivel global pero también en nuestro entorno más cercano.

\section{Sector primario y cambio climático}

Todo este proceso ha llevado a una profunda metamorfosis de numerosos elementos patrimoniales, que, a su vez, han influido en el cambio climático, sin olvidar en muchas ocasiones su aportación positiva. Así, por ejemplo, la continua mecanización y modernización de la producción agraria y ganadera en España permitió la desaparición en nuestro país de fenómenos relacionados con las hambrunas y todas sus consecuencias -enfermedades, pobreza, etc.-. No obstante, estos efectivos avances han traído como consecuen- 


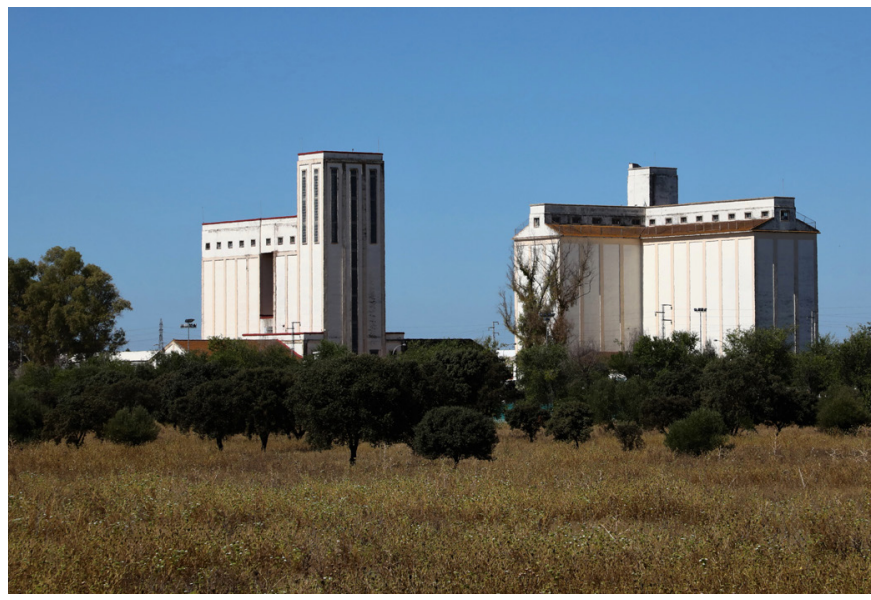

Silos de Bellavista (Sevilla)

cia, en muchas ocasiones, una sobreexplotación de los recursos que a la larga potencian el cambio del clima por el uso de productos químicos que afectan al suelo y la atmósfera; el aumento de la superficie de cultivo y la pérdida de ecosistemas que ayudaban a regular nuestro clima; la agricultura intensiva que puede llevar a la desertificación; una gestión del agua derrochadora; o la estabulación excesiva del ganado.

Pero la propia actividad agraria y ganadera, a su vez, se ve afectada por el cambio climático. Encontramos múltiples ejemplos, como el aumento de las plagas, la erosión de los suelos, las inundaciones o las sequías. El incremento de las temperaturas incide en el rendimiento de los cultivos y la alteración de la floración e, incluso, en la capacidad de resistencia del ganado (Benito 2021). Esta situación está obligando a tomar medidas que superen las políticas actuales, para ajustarse a las consecuencias del cambio (Iglesias, Quiroga y Sotes 2011, 19), como por ejemplo la modificación en los hábitos alimenticios del ganado para que las emisiones de metano se reduzcan o un uso más eficiente del agua en los regadíos (Rico 2018). Si esta situación está ocurriendo en la actividad humana, el mismo fenómeno sucede en los elementos que conforman el patrimonio natural y paisajístico.

La que se podría llamar "industrialización" de la producción agraria y ganadera ha conllevado además de estas

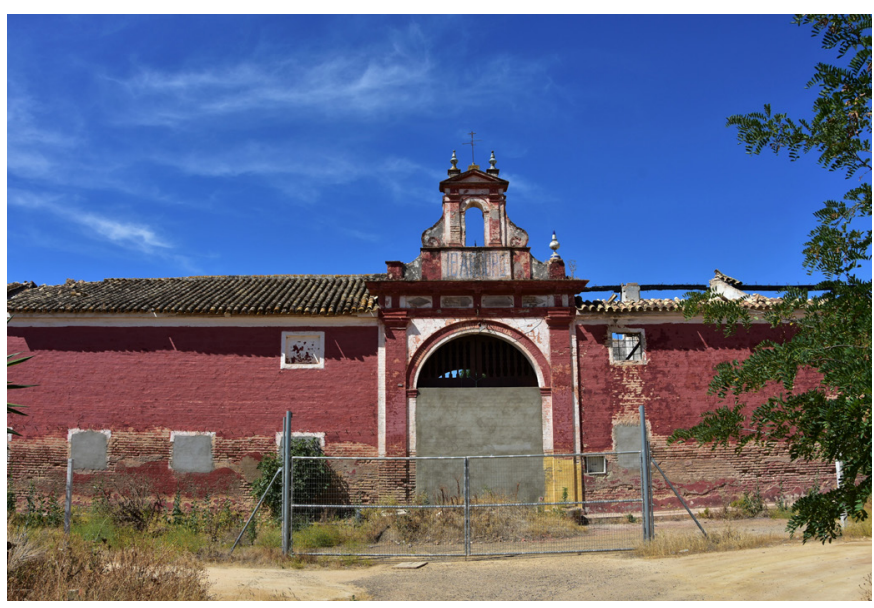

Hacienda Ibarburu (Dos Hermanas, Sevilla) | fotos José Manuel Baena Gallé

consecuencias negativas, el abandono de formas de producción tradicionales, junto con todo su patrimonio material e inmaterial, e incluso el abandono de localidades completas por el fenómeno del éxodo rural a los grandes núcleos urbanos.

Podríamos citar como ejemplo la situación de las haciendas de olivar diseminadas por todo el campo andaluz. La hacienda es una explotación agrícola que se dedicaba al cultivo del olivo y la producción de aceite fundamentalmente. Las haciendas de olivar forman un conjunto arquitectónico donde existen diversas dependencias como la residencia señorial, las almazaras para la transformación de la aceituna y las dependencias para las labores agrícolas y ganaderas (Aguilar García 1992, 27). En la actualidad muchas de ellas se encuentran en total abandono y en proceso de ruina dado que el sistema de transformación de aceituna ha variado totalmente. Sin ir más lejos, la hacienda Ibarburu en la localidad sevillana de Dos Hermanas.

Esta hacienda tiene su origen en el siglo XVII, aunque el edificio actual fue construido en 1748 con todos los elementos propios de estas instalaciones, inscrito en 2002 como BIC, con la tipología jurídica de monumento. En la actualidad se encuentra en un estado de desidia lamentable y ha sido expoliada lo que incluso ha sido señalado en la prensa local. 
Otro caso es el de los silos agrícolas españoles del siglo $\mathrm{XX}$. Aunque el fenómeno del almacenamiento de granos tuvo su origen en el neolítico y se ha ido desarrollando a través del tiempo, este se transformará totalmente con la revolución industrial y la aparición de nuevos materiales. En España resulta fundamental la aparición del problema de abastecimiento del trigo en torno a la Guerra Civil y cómo se planteó una política estatal de intervención en el proceso. Esto se ve acentuado durante el régimen franquista, que crea en 1937 el Servicio Nacional del Trigo y, en 1945, el Plan General de la Red Nacional de Silos y Graneros planificando la construcción de 437 silos y 631 graneros (Silosygraneros.es 2021). En 1984 desaparece el monopolio triguero del estado pasando muchas competencias a las comunidades autónomas e iniciándose un proceso de abandono de la red de silos española que están teniendo una suerte desigual con situaciones de ruina, ocupación ilegal o vandalismo. Estas edificaciones que marcaban un perfil especial de nuestros pueblos y ciudades se encuentran en claro peligro, como ocurre con los dos silos de Bellavista en Sevilla. La primera de estas edificaciones se construyó en 1967 y se dedicaba a la recepción y conservación del grano. El otro gran silo es de 1971 encargado de la selección de semilla. En la actualidad se está planteando un proceso de construcción inmobiliaria en los terrenos aledaños, aunque hay propuestas para su rehabilitación y reutilización.

\section{Conclusión}

La pregunta o el debate que se debería plantear sería la relación entre progreso y bienestar. La humanidad habita en el planeta Tierra, al que hay que proteger desde el punto de vista natural para poder seguir habitándolo. Pero también como comunidades de convivencia necesitamos referentes que nos enlacen con el pasado y permitan tender lazos comunes. $Y$ en ese aspecto resulta fundamental el patrimonio cultural. Cada elemento del patrimonio -material o inmaterial-que se pierde es algo irrecuperable y su ausencia supone un paso más hacia la desaparición del mundo y la vida tal y como lo conocemos.

\section{BIBLIOGRAFÍA}

- Aguilar García, M. ${ }^{a}$ C. (1992) Las haciendas. Arquitectura culta en el olivar de Sevilla. Sevilla: Universidad de Sevilla

- Benito, F.J. (2021) Así impactará el cambio climático en los cultivos y la ganadería de España. Verde y Azul, 17 de mayo de 2021. Disponible en: https://verdeyazul.diarioinformacion.com/ ganaderia-y-cultivos-bajo-el-impacto-del-cambio-climatico. html [Consulta 06/07/2021]

- Guzmán, M.J. (2021) Silos de Bellavista: los hitos invisibles del patrimonio industrial. Diario de Sevilla, 6 de junio de 2021. Disponible en: https://www.diariodesevilla.es/sevilla/SilosBellavista-hitos-patrimonio-industrial-Sevilla_0_1580543080. html [Consulta: 12/07/2021]

- Guzmán, M.J. (2019) La larga agonía de la Hacienda Ibarburu. Diario de Sevilla, 18 de septiembre de 2019. Disponible en: https://www.diariodesevilla.es/provincia/largaagonia-hacienda-ibarburu_0_1392761074.html [Consulta: 12/07/2021]

- Iglesias, A., Quiroga, S. y Sotes, V. (2011) La agricultura española y el cambio climático. Economistas, n. ${ }^{\circ} 127$, pp.19-27

- Ministerio para la Transición Ecológica y el Reto Demográfico (2021) Qué es el cambio climático. Disponible en: https://www. miteco.gob.es/es/cambio-climatico/temas/cumbre-cambioclimatico-cop21/el-cambio-climatico/ [Consulta: 12/07/2021]

- Rico, J. (2018) La agricultura española, contra el cambio climático. Campus: la revolución de las ideas, 11 de diciembre de 2018. Disponible en: https://www.fundacionaquae.org/laagricultura-espanola-contra-el-cambio-climatico/ [Consulta: 06/07/2021]

- Sciacca, F. (2021) Necesitamos tu firma. Refugiados, n. ${ }^{\circ}$ 2, monográfico El coste humano del cambio climático, p. 3. Disponible en: https://eacnur.org/files/reports/file/af_2021_ revistajunio_sp_web.pdf [Consulta: 12/07/2021]

- Silosygraneros.es (2021) Red Nacional de Silos y Graneros de España. Disponible en: https://silosygraneros.es/ [Consulta: 12/07/2021]

- UNESCO (2009) Cambio climático y Patrimonio Mundial: Estudios de caso. París: Centro del Patrimonio Mundial de la UNESCO. Disponible en: https://www.iccrom.org/sites/ default/files/2020-02/unesco_estudios-caso-cambio-climaticopatrimonio-mundial.pdf [Consulta: 12/07/2021] 